Document downloaded from:

http://hdl.handle.net/10251/105814

This paper must be cited as:

Leon, R.; Rodríguez Rodríguez, R.; Gómez-Gasquet, P.; Mula, J. (2017). Social network analysis: A tool for evaluating and predicting future knowledge flows from an insurance organization. Technological Forecasting and Social Change. 114:103-118. doi:10.1016/j.techfore.2016.07.032

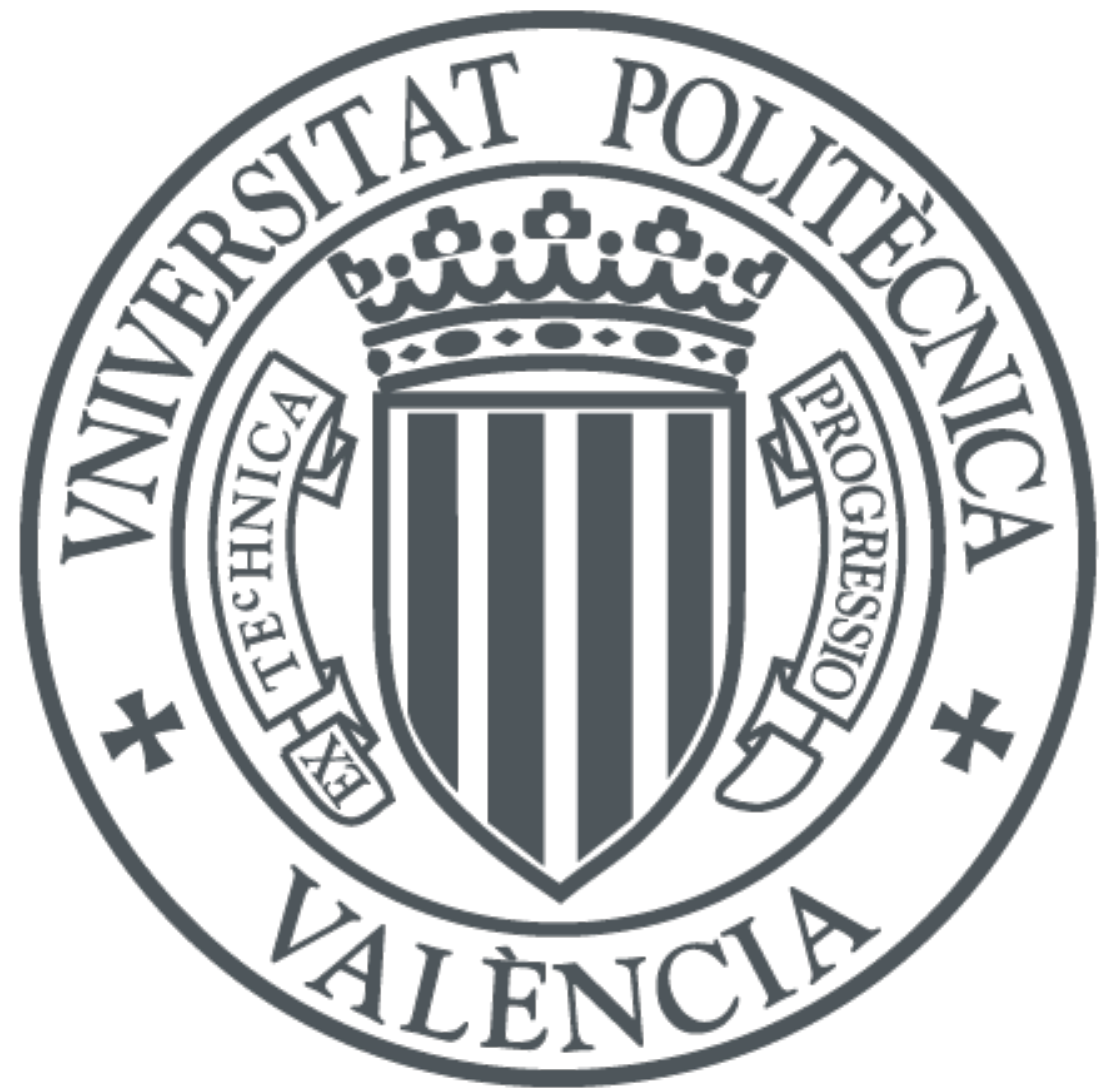

The final publication is available at

https://doi.org/10.1016/j.techfore.2016.07.032

Copyright Elsevier

Additional Information 


\title{
Social Network Analysis: a tool for evaluating and predicting future knowledge flows from an insurance organization
}

\begin{abstract}
The paper aims to identify the individuals who influence the knowledge sharing processes from an internal social network and to forecast the future knowledge flows that may cross it. Exploratory research is employed, and a four-phase methodology is developed which combines a social network analysis with structural modeling. This is applied to the internal enterprise social network used by a British insurance company. The main results emphasize the most influential groups, their relationships, future knowledge flows, and the connection between the network's heterogeneity and structure, and employees' future knowledge sharing intention. These findings have both theoretical and practical implications. The theory is extended by proving that a social network analysis can be used as a tool for evaluating and predicting future knowledge flows. At the same time, a solution is offered to decision-makers so they will be able to: (i) identify the potential knowledge loss; (ii) determine leaders; (iii) establish who is going to act as a knowledge diffuser, by sharing what they know with their co-workers, and who is going to act as a knowledge repository, by focusing on acquiring increasingly more knowledge; (iv) identify the elements that influence employees' future knowledge sharing intention.
\end{abstract}

Keywords: knowledge sharing; future knowledge flows; social network analysis; strategic planning and implementation; insurance sector.

\section{Introduction}

The current, dynamic and uncertain knowledge-based economy not only shows that knowledge and innovation go hand in hand but it also supports their transformation into critical factors for the economic growth (Grant, 1996; Nonaka and Takeuchi, 1995). Either intentionally or unintentionally employees and organizations acquire and share knowledge and such knowledge is used for further abstractions and reinterpretations to make it suitable for a certain situation or environment and acts as a precondition for innovation. For these processes to take place, it is increasingly acknowledged in the organizational studies (West and Bogers, 2014) that cooperation must be established among members and that networks must be developed.

Against this backdrop, the need for managers to develop policies and procedures that encourage both intra- and inter-organizational knowledge creation and sharing and, at the same time, that take advantage of the fast development of collaborative and communication technologies (Ahmad et al., 2014; Yin et al., 2015) is increasing. However, the analyses done so far do not answer this challenge by providing an instrument for analyzing and predicting knowledge flows. Most focus on either the influence factors of knowledge sharing (Kamoche et al., 2014) or its effects (Bianchi et al., 2011; Marrabeli and Newell, 2012), and neglect aspects like knowledge dynamics. Therefore their analysis is static, even though knowledge is dynamic and fluid and it changes shape and content from one individual to another. As the SECI model reveals, tacit knowledge may be transformed into explicit knowledge and viceversa (Nonaka and Takeuchi, 1995); knowledge flows from one individual to another or to a group and from a group to each individual. Along the way, it is enriched with new insights, ideas, thoughts, experiences etc. Still previous researches only reflect the past knowledge flows that cross the team or the organization without considering that these flows may have been used or enriched. At this level, they provide decision-makers with an image of the past which encourages them to assume that the same patterns will be followed in the future. 
Most past analyses have resulted from questionnaire- or interview-based surveys (Ritala et al., 2015; Tasselli, 2015). These appeal to the short-term memory of respondents and do not reflect real knowledge flows, but the most recent ones. A difference is made by scholars who concentrate on analyzing the knowledge sharing process that occurs in the academic community $(\mathrm{Hu}, 2013)$. In this case, the analysis is based on real data provided by articles that have been written during a given time period.

Moreover, previous studies about knowledge sharing (Bianchi et al., 2011; Kamoche et al., 2014) have tended to focus only on the "know how" and "know what" knowledge type. Although this information is useful as it helps develop a potential knowledge map, and it asserts the intangible resources that the company possesses, sometimes it is more important to know who holds the necessary resources. In fact, Huang (2009) argues that members need to understand who knows what, while $\mathrm{Hu}$ (2013) demonstrates that people with a large number of social links with others strongly impact the diffusion of innovations. Although they adopt an external perspective, Arend et al. (2014) emphasize the importance of "know-who" by proposing a knowledge disaggregation based on two dimensions: familiarity and source of knowledge, of which the latter practically defines who owns knowledge and who the "recipient" that holds it actually is.

Therefore, at the organizational level, there is a research gap related to analyzing the actual knowledge flows that occur in a company and anticipating the future knowledge sharing processes. This gap could be bridged by using social media technologies based on communication and interactions, which are capable of providing real data. These represent the starting point for a social network analysis (SNA) which is capable of empirically identifying central individuals, discovering patterns, detecting sub-groups and predicting future interactions (Chau and $\mathrm{Xu}, 2007$; Rohrbeck et al., 2015). Furthermore, knowing who knows-who may facilitate employees understanding and also the processes of knowledge sharing. On the other hand, it may bring forward who better knows what is happening in a specific area, and who is capable of mobilizing groups. However, in this area, the main focal point lies mainly on the "object" shared rather on the subjects involved in the process.

Basically, the main gaps identified in the knowledge management literature are related to: (i) using data from secondary and subjective sources (questionnaires, interviews etc.); (ii) analyzing knowledge flows from a static perspective although knowledge dynamics is well recognized; and (iii) neglecting who knows what knowledge type. Therefore, the main research question would be: could an SNA serve as a tool to evaluate and predict the future knowledge flows that may cross an internal enterprise social network?

Hence, we aim to address the research challenges mentioned herein. The current paper is organized as follows: Section 2 highlights the nexus that links knowledge sharing, knowledge loss and SNA. Then, Section 3 moves forward by proposing a methodology to analyze the knowledge sharing process from an internal social network and by predicting the future knowledge flows that may occur among an insurance company's employees. Following these coordinates, Section 4 presents the main research findings and then Section 5 discusses the major implications and limits of our insights. This article closes by drawing a couple of conclusions and offering further research directions.

\section{Literature review}

2.1. Enterprise social networks: an external and internal approach

Given the high level of dependence recorded among individuals and companies, a new economy emerges, called socialnomics (Qualman, 2009), economy of relations (Robison and Ritchie, 2010) or economy of integrity (Bernasek, 2010). This is based on trust and integrity (Fernandes et al., 2016) and its development is supported by the enterprise social networks. 
From an abstract perspective, an enterprise social network is a web-based platform that "supports users in contributing persistent objects to a shared pool, which enables public responses to these objects, allows profile information to be presented, and connects users via features like Following or Friendship request" (Behrendt et al., 2014, p.560). From a restrictive perspective, an enterprise social network is a web-based platform which allows "workers to: (1) communicate messages with specific coworkers or broadcast messages to everyone in the organization; (2) explicitly indicate or implicitly reveal particular coworkers as communication partners; (3) post, edit, and sort text and files linked to themselves or others; and (4) view the messages, connections, text, and files communicated, posted, edited, and sorted by anyone else in the organization at any time of their choosing" (Leonardi et al., 2013, p.19). As it can be notice, both approaches emphasize the importance of sharing explicit and tacit knowledge inside and outside companies' boundaries, and highlight the two research directions adopted in previous studies.

One research stream concentrates on external enterprise social networks, described as hedonic systems that provide enjoyable experiences while satisfying users' emotional needs (Premkumar et al., 2008), and brings forward the advantages of using them to establish sustainable relationships with firm's external stakeholders. According to Wyld (2008) the firms that communicate with their customers using Facebook or Twitter improve their corporate image. Other studies go further and present these platforms as an opportunity for: (i) obtaining research and technical support (Evans, 2008); (ii) building brands and increasing customer's retention (Fernandes et al., 2016); (iii) recruiting (Pei et al., 2011); and fostering internationalization (Zhou et al., 2007).

The other research stream receives less attention from management academics and practitioners, and focuses on the advantages and disadvantages of using an internal enterprise social network; this is perceived as a hedonic and utilitarian system that increases employees' communication effectiveness and efficiency (DiMicco et al., 2009). According to previous studies the use of an internal social network tends to: (i) connect groups of individuals who do not share the same physical space or cultural profile (Shirky, 2008); (ii) increase employees productivity and motivation (Chui et al., 2012); (iii) positively affect employees' performance (Zhang and Venkatesh, 2013; Wu, 2013); (iv) improve communication and collaboration (Kwahk and Park, 2016; Sarker et al., 2011); (v) allow managers to identify experts and informal networks, and to access their resources (Behrendt et al., 2014); and (vi) foster individual and organizational learning (Scott et al., 2016). According to Qualman (2009), networked employees can be successfully involved in innovation, wealth creation and socio-economic development.

Nevertheless, the outputs generated by the internal and external enterprise social networks depend on the company's financial and timely investments in information technology and on employees' informational systems proficiency (Kane and Borgatti, 2011). They must know how to create content, how to foster stakeholders' involvement, and how to analyze and interpret the results. If the first two issues can be solved through training programs, the same cannot be claimed when it comes to the last aspect. As Behrendt et al. (2014) argue, there is paucity of research that develops analytical methods capable of extracting the added value of an enterprise social network and using it in managerial decision making, and an SNA alone is insufficient (Kane et al., 2014; Venkatesh et al., 2013).

Another problem that is brought forward only at the internal social network level is related to employees' psychological isolation. Kane et al. (2014) state that using an internal enterprise social network could reduce the variety of real-life relationships that, in the long term, could reduce employees' direct interactions, which would generate their psychological isolation. In other words, they would become better in virtual communication and the use of social skills in real life would diminish. These assumptions are contradicted by Zhang and 
Venkatesh (2013) who prove that online communications complements, rather than replaces, offline communications.

\subsection{Knowledge sharing: Know what, know who, know why and know how}

In the last 50 years, knowledge has become a critical factor for company's success and the hardest one to define. Some researchers adopt a social approach (Nonaka and Takeuchi, 1995; Nonaka and van Krogh, 2009) and present knowledge as a metaphor or fluid capable of incorporating an organized set of factual declarations, ideas and experiences, shared systematically with others by using a common communication environment. Others support the technological perspective (Yoo and No, 2014) and claim that knowledge defines the contextualized information that is processed and shared with the help of information technologies. In the first case, the human character of knowledge is emphasized, while the abstract dimension is highlighted in the second. However, both the abstract and subjective dimensions must be taken into account since knowledge represents the complex model of thinking, feeling and behaving, developed by passing contextualized information through an internal, personal filter.

If knowledge visibility is considered, a distinction is made between explicit and tacit knowledge (Nonaka and Takeuchi, 1995). Explicit knowledge has a universal character, is visible and can be used in various contexts (Nonaka and van Krogh, 2009); it is available at the conscious level and is based on rational, convergent and logic thinking. As a result, it is shared through words, propositions, and phrases, and is stored, at the organizational level, in documents, reports, procedures and rules. Therefore, it is most useful when the company has to deal with routines, and with organized and predictable situations (Eisenhardt and Martin, 2000; Teece et al., 1997). Tacit knowledge is personal, less visible and hard to formalize. It reflects individuals' perspectives, intuitions, values, beliefs and hunches, and is entailed in their actions, experiences, ideas and emotions (Nonaka and Takeuchi, 1995). It is available at the unconscious level and represents the result of creative, divergent thinking. As a result, it is shared through interpersonal interactions and can be stored as part of organizational culture. It is important in unpredictable and disorganized circumstances that require innovative solutions. Thus, if explicit knowledge is the "core" of an organization, then tacit knowledge may be seen as the "blood" that makes teams move in the desired direction by transforming the desired organizational vision into reality.

If the knowledge subject is taken into account, a distinction is made among: know what, know why, know how, and know who (Garud, 1997). The first category reflects facts and has a powerful practical character; it shows what needs to be done in certain circumstances and is stored as organizational practices and conduct norms. The second category focuses on the rational processes that stimulate action and brings forward scientific knowledge on generally accepted principles and rules; it has a meditative character and it facilitates the understanding of the cause-effect relationships. It can be stored as organizational notes, rules, procedures and documents. The first two categories are fundamental when the environment has to be analyzed and a future direction has to be established. In such circumstances, it is crucial to have access to the right knowledge type (know what) and to be able to understand how things work, what causes specific actions and what effects they may have (know why). The third category concentrates on the abilities and mode of action. It is practical in nature, is the result of experimental learning and it is incorporated into organizational routines and processes. Last but not least, the "know who" category uncovers experts from a given field and the relationships established among them. It incorporates knowledge about those who know what to do and how to do it. The last two knowledge categories strongly influence on organization since the former shows how to manage the process and the latter indicates key individuals; in other words, "know how" 
emphasizes the steps that must be followed to transform the desired organizational vision into reality while "know who" brings forward the individuals who should conduct action or who should be involved in mobilizing teams/departments.

Regardless of the perspective adopted in defining knowledge, academics seem to agree that knowledge needs to be acquired, created, interpreted, combined, shared and used inside and outside organizational boundaries (Nonaka and Takeuchi, 1995). Most of the literature from the knowledge management field concentrates on discovering either the influential factors or the effects of knowledge sharing. Studies from the first category assert that willingness to share, interactions and communication play a critical role in the knowledge sharing process (Kamoche et al., 2014), whereas trust has a positive influence on the quality and quantity of knowledge sharing (Deng et al., 2014). Studies from the second category prove that knowledge sharing is directly correlated with firm performance, and with gaining competitive advantages (Bianchi et al., 2011), innovation capabilities (Huizingh, 2011), and productivity (Marrabeli and Newell, 2012; Nonaka and Takeuchi, 1995).

Despite these insights, previous studies refer mainly to "know what" and "know how", and neglect the influence that the "know who" and "know why" may have at the organizational and inter-organizational levels. The issue is brought forward by Nicolini (2011) who evokes the need to analyze the knowledge rooted in an extended pattern of interconnected activities. So, this perspective is subjected to interpretation because there is no clear demarcation as to whether the subject of analysis should be "know how" or "know who". The author does not state whether the focus is on the actors or on the intangible assets involved in the activities. The first will increase the understanding of individuals, teams, groups and organizations of who knows what and will improve the knowledge sharing efficiency. This information has been treated as being valuable in the more recent studies that discuss the knowledge leakage problem in inter-firm collaboration (Ahmad et al., 2014; Ritala et al., 2015). Knowing who the gatekeepers are that control the knowledge flows is critical in inter-organizational relationships, and is somewhat ignored at the intraorganizational level. Nevertheless, plenty of research has been done to identify the roles that individuals play in external social networks, like Facebook, Twitter, Google+, LinkedIn etc. (Chang et al., 2015; Trusov et al., 2010) and which emphasizes the fact that users play wide ranging roles and it is critical to determine who influential leaders are.

An individual may act as a knowledge diffuser, knowledge repository, knowledge gatekeeper, or knowledge broker (Table 1). A knowledge diffuser is a person who is oriented towards cooperation and who focuses on establishing multiple relationships in order to ensure that his/her ideas are disseminated among his/her co-workers (Cyr and Choo, 2010; Sakalaki and Sotiriou, 2012); the focus is on knowledge transmitting. A knowledge repository is a person who adopts individualist behaviour and focuses on establishing multiple relationships in order to ensure that he/she acquires increasingly more knowledge from his/her co-workers (Cyr and Choo, 2010; Sakalaki and Sotiriou, 2012); here the focus lies on knowledge acquisition. When groups are involved, a difference between knowledge brokers and knowledge gatekeepers must be made. The first describes the persons who mediate the knowledge sharing process between two other members by acting as a bridge that links two individuals who have no direct relationship with each other (Baer et al., 2015). The last category, knowledge gatekeepers, includes those persons who act as intermediates in the relationships established among groups; they control the knowledge flows that go in and out of certain groups (Foster et al., 2011; Soroka, 2012). 
Table 1. The roles of individual A in an internal social network



However, the roles that individuals play in the knowledge sharing process seem to be neglected in the knowledge management area. No models have been developed to date that distinguish among the knowledge diffusers, knowledge repositories, knowledge gatekeepers, and knowledge brokers, and based on the knowledge flows that they control or could control in the future.

Nevertheless, knowledge flows from the individual level to the group and company level is transformed on the way, it into form and content terms. This issue is neglected by scholars who argue that innovation is the commercial application of new knowledge (Love et al., 2011; Singh et al., 2015) but focuses on past knowledge and not on current or future knowledge. Their analysis is static and reflects past knowledge flows without taking into account that these flows have already been used or enriched by new insights, ideas, experiences etc.

\subsection{Knowledge sharing in internal social networks}

These gaps could be filled by combining the network theory with the social exchange theory; the first focuses on the relationships established among individuals, while the latter concentrates on the reasons that lie behind these relationships. In other words, the social exchange theory (Smith et al., 2014; Tsai et al., 2013) assumes that knowledge sharing appears after a more or less conscious costs-benefits analysis; costs usually describe the time and energy spent during the process of transforming tacit knowledge into explicit knowledge and, conversely, benefits include "the obligation by others to reciprocate, heightening of selfesteem, increased self-efficacy, increased personal identification with coworkers, respect from others, reputation, and enjoyment in helping others" (Cyr and Choo, 2010, p.827). Since a social network is presented as a cluster of people who develop some patterns of contact and interactions, mainly based on friendship, business or cooperative relationships (Ye et al., 
2013), these elements are reflected, at an abstract level, by the number of likes, followers and friends, and also by the network structure.

According to the traditional social network theory, two opposing approaches co-exist; some researchers (Centola and Macy, 2007; Reagans and Zuckerman, 2008) argue that the actors from embedded networks are better coordinated, trust each other and better develop communication skills while others (Al-Oufi et al., 2012; Burt, 2001) claim that the individuals who connect with the most isolated members take advantage of connecting with new members and accessing new information and knowledge. Therefore, making the difference between critical and isolated members (nodes) of a network becomes crucial. These complement the findings of the social value orientation theory (Cyr and Choo, 2010 Sakalaki and Sotiriou, 2012), which distinguishes between people who focus on cooperation and those who adopt an individualist behavior; the former are oriented towards developing multiple ties with network members by acting as knowledge diffusers, while the latter choose to stay away by acting as knowledge repositories. At this level, concepts like degree centrality, betweenness and closeness centrality are brought forward as they capture network heterogeneity and structure and their analysis is assumed critical (Zhu et al., 2010).

Degree centrality reflects who the most popular actors are by measuring their influence on the network (Albert et al., 2000; Zhu et al., 2010). Those with a high degree centrality are those who control the resources shared in the network. Therefore, they are seen as the network's “Achilles Heel” (Albert et al., 2000). They are capable of successfully diffusing resources in the network; indeed the network may fall apart if they leave. Zhu et al. (2010) go even further and state that moving the members with high degree centrality out of their networks disrupts knowledge movement. Their statement is supported by the fact that hyperlinked persons act similarly to opinion leaders (Hu, 2013) as they influence the group members with whom they interact. Consequently, their disappearance may lead the network to a confusing situation by not knowing to whom to return for advice or a possible solution. However, studies on the matter are based mainly on the induction and lack of empirical evidence.

Betweenness centrality emphasizes an actor's power in a network by measuring his/her capacity to intermediate resource sharing among various network members and to connect with isolated ones ( $\mathrm{Lu}$ et al., 2010). It stresses the role that each member plays in the network: gatekeeper, broker, diffuser or repository. As a result, knowing the level of betweenness centrality of each employee is very useful information for decision-makers since it makes the difference between the actors who control the flows that go in and out of certain groups and those who contribute little or nothing to the network's development. The disappearance of those who define the first category may cause the network's fragmentation while those defined as the latter possibility go unnoticed.

Closeness centrality underlines actors' capacity to easily spread their resources to all other network members. Employees with a high degree of closeness centrality stimulate sharing and using explicit knowledge.

To summarize, internal social networks, if properly managed and users are well-trained, could be extremely beneficial for organizations. This paper presents a novel methodology that distinguishes it from previously developed approaches due to the fact that it: (i) is based on real data, provided by an online enterprise social network; (ii) concentrates on the internal environment and not on the external one; (iii) emphasizes who knows who and not only who knows what; (iv) highlights the future knowledge flows that cross the internal social network, based on a P1 model; and (v) reflects the nexus between networks' heterogeneity and structure and employees' future intention to share knowledge with one another. 


\section{Research design}

\subsection{Research hypotheses}

This paper follows an exploratory research approach, where an SNA-based methodology is presented and applied to an insurance organization. Linked to the previous literature review section, since degree, betweenness and closeness centrality define the network's heterogeneity and structure, and bring forward the roles adopted by the internal social network members, three hypotheses are put forward:

Hypothesis 1: Network heterogeneity and structure are associated with employees' future knowledge sharing intention.

Hypothesis 2: Network heterogeneity and structure are associated with employees' future intention of being knowledge repositories.

As part of the modern social network theory, the distinction is made between the structuralist and connectionist approaches which analyze the way ties and their functions are treated from different viewpoints (Borgatti and Li, 2009). The first considers ties to be a topology, while the latter perceives ties as flows of resources. In the first case, measured interactions are seen to describe a topology on or through which phenomena of interest are assumed to occur. In the second case, links represent the actual flows of interest. We adopt this perspective further since it is the more appropriate one in the knowledge management field; knowledge flows that characterize human interactions are no assumption but a certainty. In an ordinary communication, individuals share emotions, values, ideas and experiences which constitute explicit and tacit knowledge. Therefore, they cannot remain isolated forever. As previously mentioned, individuals' decision of getting involved or not, in a future knowledge sharing process is strongly influenced by estimated outcomes (Cyr and Choo, 2010; Sakalaki and Sotiriou, 2012; Smith et al., 2014). Thus, it can be assumed that those who act as a knowledge repository could become knowledge diffusers in the future. Formally:

Hypothesis 3: There is a significant correlation between employees' future intention of acting as a knowledge repository and that of encouraging knowledge sharing.

In order to fill the gaps identified in the knowledge management literature, we aimed to develop a methodology capable of analyzing current knowledge flows and predicting future ones. This will complement the research done by Lind and Sulek (2000) who forecast project duration for knowledge workers; the difference between both works is that the cited authors analyze the output generated by knowledge sharing, while we concentrate on the process.

\subsection{Research model and methods}

In order to determine which individuals influence the knowledge sharing process from an internal social network, and in order to forecast future knowledge flows a four-phase methodology was developed (Figure 1), where each phase includes a set of unique and interdependent activities. 


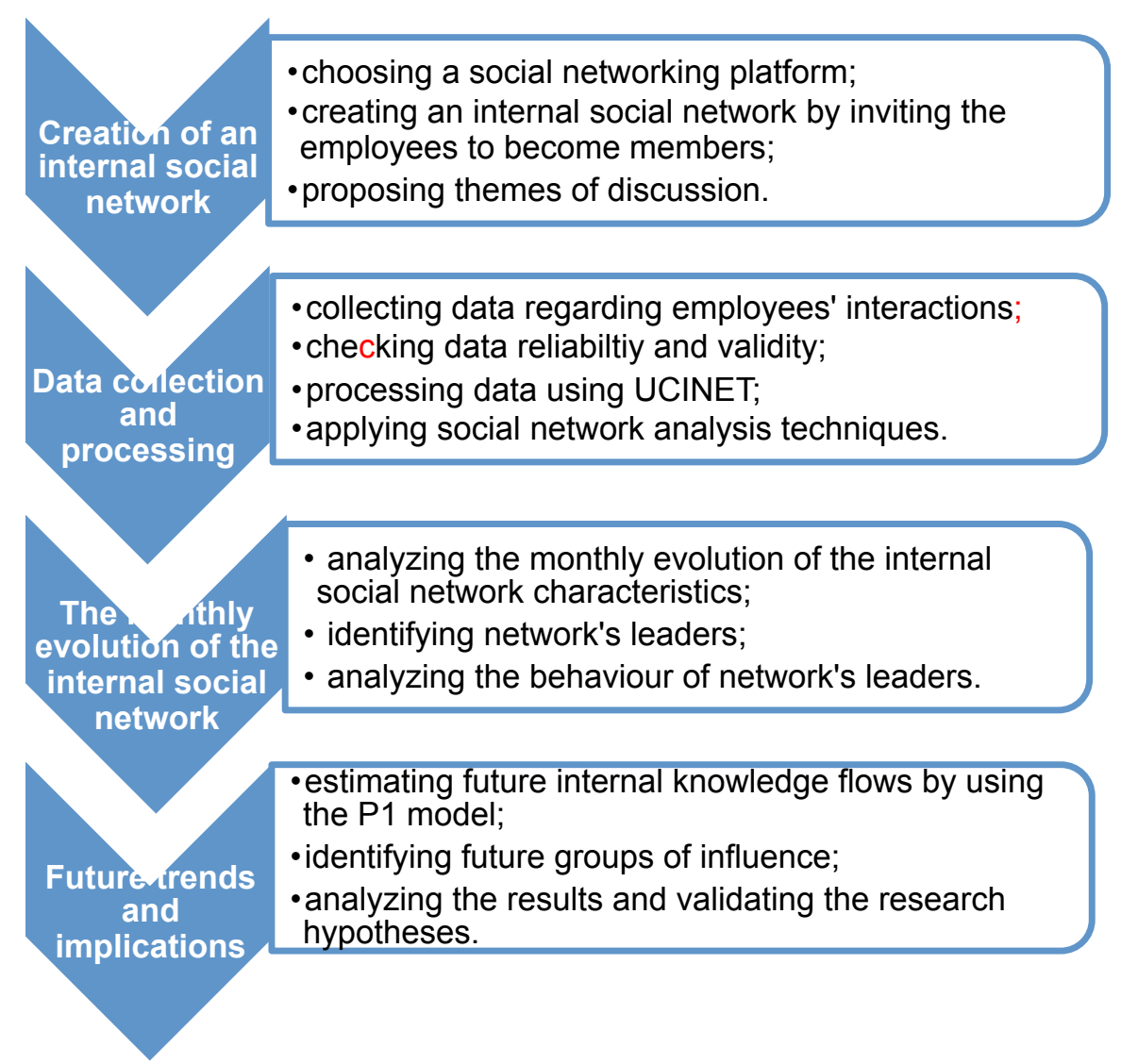

Figure 1. Proposed methodology

\section{Phase 1. Creating of an internal social network}

Firstly, the companies interested in taking advantage of new digital technologies, and which wish to facilitate and support internal knowledge sharing, have to choose a social networking platform. Their choice will be mainly influence by license cost, level of security, available features and how easy it is to use. After making a choice, employees will be invited to become members of the internal social network and conversations will commence.

\section{Phase 2. Data collection and processing}

Once the network starts having a life of its own (the moderator no longer interferes with stimulating conversations among members), the next phase can start. This emphasizes the operational aspects of the methodology and concentrates on data collection, checking data reliability and validity, processing them by UCINET, and applying SNA techniques.

Data are collected from the internal social network. They are provided by the system's administrators in an accessible form. Then, in order to ensure data reliability and validity, several measures can be taken. Although using data from an online social network should guarantee data reliability and validity, several problems may occur (Bernard et al., 1981; Wuchty and Uzzi, 2011). As suggested by Howison et al. (2011), two techniques can be applied for evaluation. The first involves an interview with the system's administrators in order to decide whether data have been manipulated or not. The second concentrates on validity checks and aims to determine anomalies like unreasonable truncations, steps, and phase changes.

If data are reliable and valid, they are then processed by using the UCINET 6 software. This involves creating a symmetric binary matrix where "1" highlights the existence of a knowledge flow between two employees and " 0 " otherwise. As a result, the internal social 
network is presented as a symbiotic network system that includes nodes and lines; nodes represent employees, while lines define knowledge flows.

Furthermore, SNA techniques like centralization and power analysis (degree, betweenness, closeness centralization), and cohesion analysis (network density) are applied.

Degree centrality (DC) measures the actors' influence on the network according to the number of direct relationships they establish with other members. To determine the degree centrality of each employee who participates in knowledge sharing in an internal social network, we use the following equation (Freeman, 2004; Wasserman and Faust, 1994):

$$
D C(i)=\sum_{i}^{n} x_{i j}
$$

where $i$ - the analyzed actor;

$j-$ all the other actors;

$n$ - total number of network members;

$x_{i j}$ - the adjacency matrix in which each cell is defined as 1 if actor $i$ shares knowledge with $j$ and 0 otherwise.

Betweenness centrality (BC) measures the actors' capacity to intermediate knowledge sharing among various network members according to the number of geodesics (shortest paths between two actors) that cross through them (Lu et al., 2010). Its level is established as follows (Freeman, 2004; Bogartti and Li, 2009):

$$
B C(i)=\sum_{j<k} g_{j k}(i) / g_{j k},
$$

where $g_{j k}$ - number of geodesics that connect actor $j$ and $k$;

$g_{j k}(i)$ - number of geodesics which actor $i$ is on.

Closeness centrality (CC) represents the average distance of a member to all the other members. It is determined by (Wasserman and Faust, 1994):

$$
\begin{aligned}
& C C(i)=\left[\sum_{j=1}^{n} d(i, j)\right]^{-1}, \text { where } \\
& d(i, j)=\min \left(x_{i h}+\cdots+x_{h j}\right),
\end{aligned}
$$

where $h$ are intermediary actors on the paths between actor $i$ and $j$.

Network density (ND) indicates the intensity of the network's exploitation and defines the proportion of possible links that are actually present (Giuliani and Pietrobelli, 2011). It is used as a measure of efficiency and is determined following the equation developed by Wasserman and Faust (1994) as so:

$$
N D=\frac{A C}{P C}
$$

where $A C$ - number of connections that are established in the network;

$P C$ - number of potential connections that may be established in the network.

The number of potential connections (PC) depends on the number of actors involved in the network and is determined according to:

$$
P C=\frac{n(n-1)}{2},
$$

where $n$ - total number of network members.

Phase 3. The monthly evolution of the internal social network

The results generated by SNA techniques are used to analyze the monthly evolution of the network's characteristics by identifying network leaders, and analyzing their behaviour. 
Past evolution reflects the knowledge flows that cross the internal social network during a given time period while current evolution is that which comes closest to the time of data collection.

The network's density is based on the assumption that all the nodes and links that exist in a network are known and it makes the distinction between "real" and "potential" relationships. From a knowledge management perspective, a "real" relationship involves an actual knowledge flow while a "potential" relationship describes a knowledge flow that may occur between two actors who, for some reason or other, have not yet interacted. It reflects the gap between the operational and potential knowledge sharing process.

Then the role that each member plays in the internal social network is taken into account. Degree centrality is considered for identifying leaders; the employees who obtain a high score become leaders or experts; they know what they know and are open to share it and, at the same time, they know what they do not know and are interested in acquiring it.

This information is complemented by that provided by betweenness centrality which indicates the role that each member plays in knowledge sharing. It allows the identification of knowledge brokers and knowledge gatekeepers. Knowledge brokers facilitate knowledge sharing between two other members while knowledge gatekeepers control the knowledge that goes in and out of certain groups. The actors with high betweenness centrality are those who frequently act as a bridge between other members.

Last, but not least, closeness centrality becomes a subject of interest. At this level, a centralized actor is capable of sharing his/her knowledge with all members by crossing a small number of relationships. Therefore, he/she knows who the gatekeepers are and how they can be approached. In this way, what he/she shares reaches everyone.

\section{Phase 4. Future trends and implications}

Based on the previously obtained results, this phase focuses on not only estimating future knowledge flows and groups of influence, but also on emphasizing potential knowledge loss.

In order to predict future knowledge flows, Holland and Leinhardt's P1 model is used. This estimates the dyadic relationships that may appear among actors based on each actor's key relational attributes, and on those of the community.

The model is based on three equations that aim to determine the probability of developing future reciprocated relationships $\left(m_{i j}\right)$, asymmetric relationships $\left(a_{i j}\right)$, and null relationships $\left(n_{i j}\right)$ among the network's actors. According to Holland and Leinhardt (1981), these are:

$$
\begin{gathered}
m_{i j}=\Lambda_{i j} \exp \left(\rho+2 \theta+\alpha_{i}+\alpha_{j}+\beta_{i}+\beta_{j}\right) \\
a_{i j}=\Lambda_{i j} \exp \left(\theta+\alpha_{i}+\beta_{j}\right) \\
n_{i j}=\Lambda_{i j}
\end{gathered}
$$

where $\Lambda_{i j}$ - global scaling parameter for the pair of actors $i$ and $j$;

$\rho$ - global tendency in the whole network toward reciprocity;

$\theta$ - overall network density;

$\alpha_{i}, \alpha_{j}$ - out-degree ("productivity", "expansiveness") of actor $i$, respectively $j$;

$\beta_{i}, \beta_{j}$ - in-degree ("attractiveness", "popularity") of actor $i$, respectively $j$.

Holland and Leinhardt's P1 model is selected instead of Fienberg and Wasserman's proposal because it is based on an exponential function; this is the most appropriate one for analyzing knowledge flows because their evolution does not follow Newtonian linear logic. 
Knowledge is dynamic and grows exponentially from one member to another; each member correlates the acquired knowledge with previous knowledge and he/she incorporates his/her own emotions, values, and other forms of tacit and explicit knowledge.

Then, the relationship between network heterogeneity and structure and future knowledge flows (Figure 2) is analyzed. Partial Least Square - Structural Equation Modeling (PLS-SEM) is applied as it is a versatile technique, capable of testing path models (Hajli et al., 2015; Marcoulides et al., 2009; Steenkamp and Baumgartner, 2000).

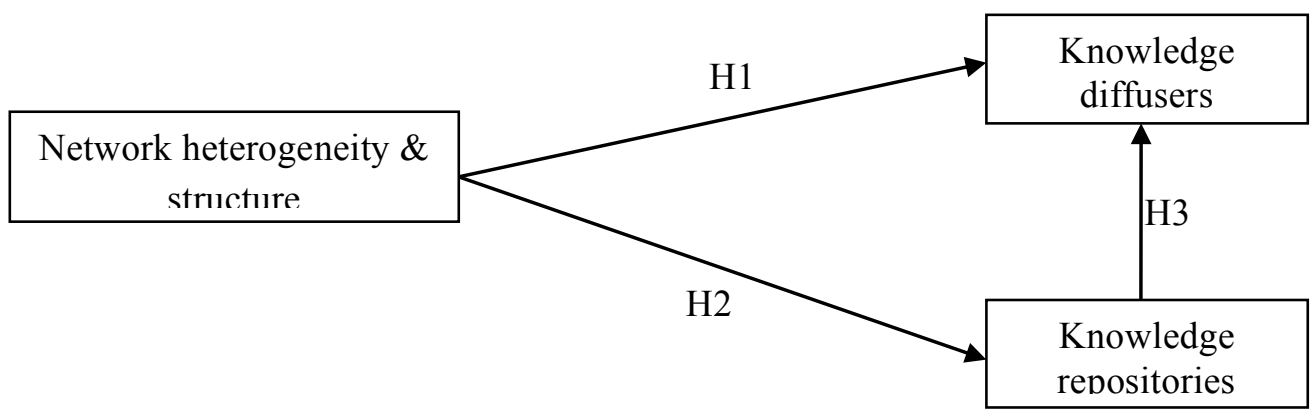

Figure 2. Theoretical model

By analyzing the status account, any potential knowledge loss can be determined. Some members may leave the network and their action might block users' access to their knowledge, change the structure of groups and modify the network's dynamic.

Starting from the results generated by these analyses, the future groups of influence are estimated. Therefore, managers will be able to determine who will exercise a greater (emotional and spiritual) pressure on certain employees. These persons should be taken into account because: (i) they have a certain area of expertise; (ii) their expertise and informal authority is recognized by others; (iii) they know what is happening inside the organization/department/group; and (iv) they know how to make others react.

Synthesizing, the proposed four-phase methodology facilitates the objective identification of those who may influence the knowledge sharing process from an internal social network and estimations of future internal knowledge flows. It is based on the real data provided by an online internal social network and it offers specific arguments to decide about who is to form part of the managerial team when it comes to develop organizational policies and practices.

\section{Application and results}

When selecting the firm in which the proposed methodology is to be applied, we concentrate on the British service sector and apply the following selection criteria: (i) operating in a dynamic and highly unpredictable market; (ii) adopting innovative behavior; (iii) recording a financial benefit in the last 7 years (post-economic crisis period), and (iv) being interested in developing and using an internal enterprise social network. The first criterion highlights the need to anticipate and faster adapt to market challenges; in order to succeed, the firm has to create, acquire and use knowledge (Grant, 1996; Marabelli and Newell, 2012). The second criterion emphasizes the company's capacity to transfer and transform the acquired knowledge while the third one brings forward the efficiency and efficacy of the internal processes. Using an enterprise social network proves that managers have understood the importance of sharing knowledge among employees, and they have decided to use the current technological progress to foster knowledge creation, dissemination and use. Last, but not least, they are concerned about identifying the company's informal 
leaders, the persons who manage to capture other's attention and involvement, and those who could act as facilitators or obstacles in the knowledge sharing process.

Based on these, we selected a British insurance company which we dubbed SPUK, because of confidentiality issues. This firm has been profitable in the last 7 years, has a history of innovative behaviors (including both product and process innovations) and is interested in using new digital technologies to improve knowledge sharing. The obtained results are presented below.

\section{Phase 1. Creating an internal social network platform}

At the end of 2013, SPUK developed an internal enterprise social network using Yammer ${ }^{\circledR}$ (Schonfeld, 2008). Yammer ${ }^{\circledR}$ Enterprise Social Network forms part of the Office 365 product suite, and allows knowledge sharing through file distribution and messages posting. The process may focus on either events or special topics (incorporated as pages) and can be made available to all members or only to a certain group. It is used in $85 \%$ of the Fortune500 firms, cultivates a sense of community, and leads to better teamwork (Leroy et al., 2013).

Employees were invited to become network members and started to exchange knowledge about their work activities.

\section{Phase 2. Data collection and processing}

Using a random sampling technique, according to which each individual is chosen by chance and all the members of the research population have an equal chance of being selected, we extracted a sample of 100 employees and we focused on the pages that each created or participated in to develop them in Yammer ${ }^{\circledR}$, from February 14, 2014 to February 16, 2015. We applied a content analysis to determine the employees who were directly involved in knowledge sharing; the relationship was codified as a "dummy" variable, where 1 represents presence of knowledge flows, and 0 otherwise; using the "reply to" messages structure to define presence of a knowledge flow is a valid measure (Wu et al., 2007).

In order to ensure data reliability and validity, several measures were used. First, we interviewed the system's administrators to decide whether data had been manipulated or not; we established that data had neither been modified nor lost in the last 12 months. Second, we focused on determining whether anomalies like unreasonable truncations, steps, and phase changes had been recorded. Since both techniques offered a positive result, data were considered both reliable and valid.

We used triangulation to validate measurements; classical and bootstrap methods were applied. The first assumes that all observations are independent while the second one constructs 5,000 networks using various sub-sets of nodes. Both methods offered statistically significant results.

Data were processed with the UCINET 6 software and techniques like systematization, tabling and graphic representation were applied. We abstracted SPUK's internal social network into a symbiotic network system, which included nodes and lines; nodes represented SPUK's employees while lines defined knowledge flows. The main variables included in the analysis were: network density, degree, betweenness and closeness centrality.

\section{Phase 3. The monthly evolution of the internal social network}

At this level we concentrated on the network's characteristics, identification of leaders and behavior. Firstly, we emphasized the knowledge flows that crossed SPUK's internal social network for 1 year. According to data presented in Figure 3, 54 employees used the internal social network for sharing knowledge whereas the other 46 remained isolated. These continued connecting to the network but did not interfere with its development, by generating 
knowledge flows. This behaviour could have multiple causes; it could either represent an area for improvement in internal communication and cooperation processes, or could be generated by individuals' traits. The employees left outside could either be uninterested in communicating with co-workers, not really willing to share their knowledge in an online environment or do not know how to do this. Further research is needed to establish the causes of their lack of involvement. Decision-makers should pay attention to this phenomenon because it could reflect either an area in which to work on (e.g. organizational culture) or an issue that should be addressed by the human resources department as part of professional development programs.

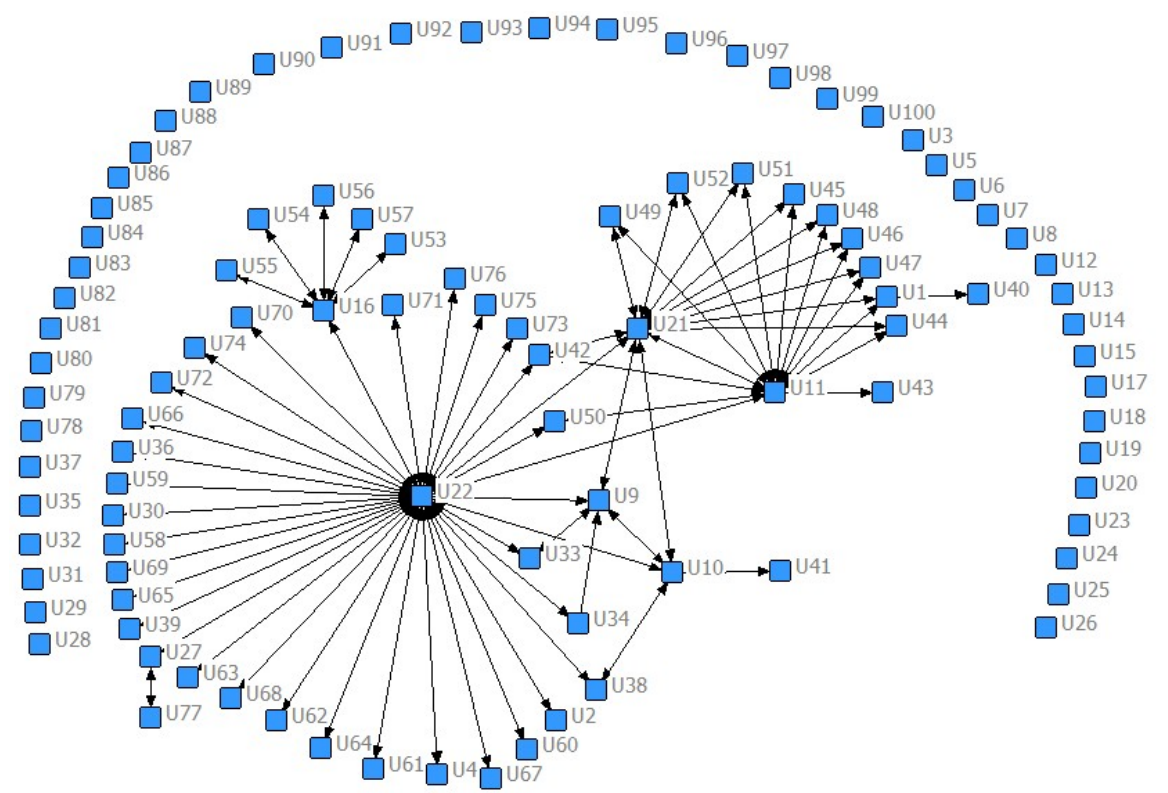

Figure 3. The relationships established among SPUK's employees

Furthermore, as we can see from Figure 4, where each shape and color represents a different department, most employees used the internal social network to support interdepartmental knowledge sharing. Therefore, it can be assumed that SPUK's employees remained faithful to traditional knowledge sharing processes (conversations, emails etc.) when it came to routines and specific job-related issues, and were open to using a more modern approach when it came to organizational issues. In other words, SPUK's employees tended to use the internal social network for socializing (sharing emotional and spiritual knowledge with their co-workers) and also for ensuring the organization's strategic and operational alignment. This assumption was supported by the fact that most of the employees who used this platform for intra-departmental knowledge sharing came from a department that was related with internal communication (U9, U10, U11, U21, U22, U33, U38, U50) and price strategies (U16, U54). 


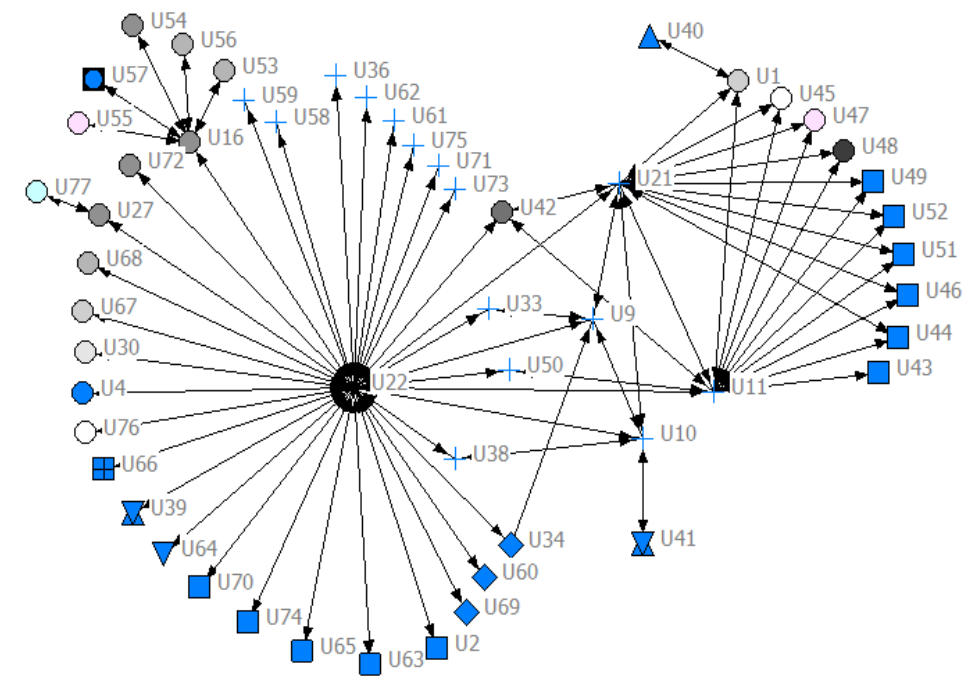

Figure 4. Distribution of SPUK's employees based on the department to which they belong

After analyzing the discussion themes, six main topics were identified, namely: (i) internal communication; (ii) corporate strategy and projects development; (iii) best practices and operational issues; (iv) marketing strategies and policies; (v) local issues; and (vi) events. Regarding the first two (Figure 5), we remark that most employees tended to use the platform to share their opinions and ideas about corporate strategy and projects development; only a few of them were also interested in internal communication, namely: U9, U10, U22, U33, and U34. Special attention must be paid to U16 and U41; the first one is a manager and uses the platform in order to share knowledge about the corporate strategy and projects development with U22, but he/she disseminates another knowledge type with the group that he/she manages. The same approach is adopted by U41, who shares his/her knowledge with $\mathrm{U} 10$, but only on corporate strategy and projects development matters.

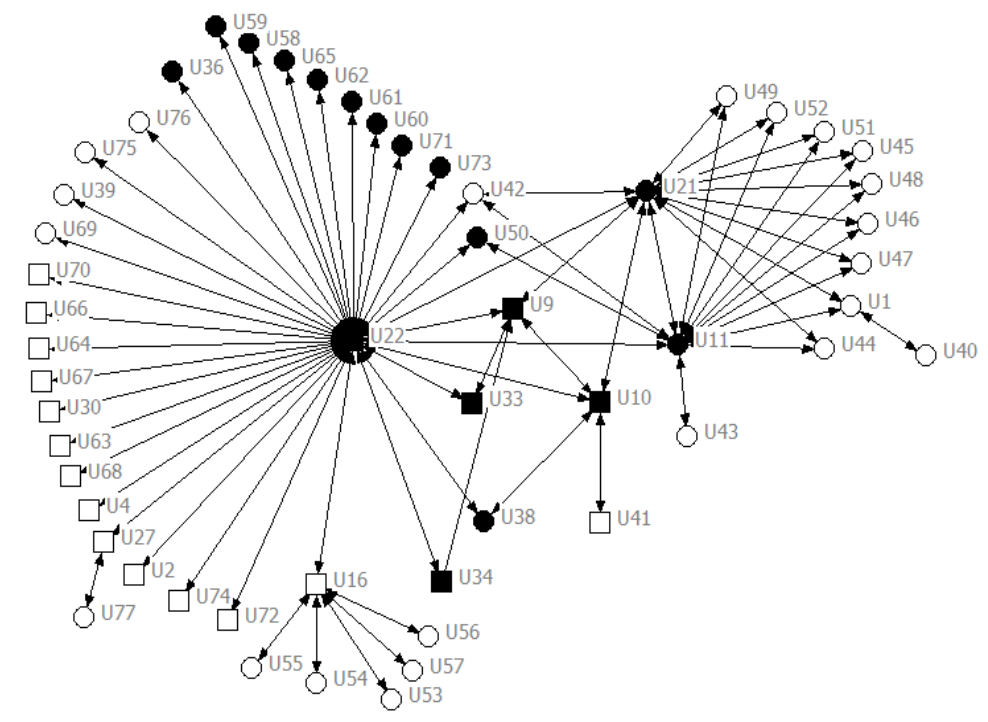

Figure 5. Distribution of SPUK's employees based on their interest in internal communication and corporate strategy and projects development

(black dots denote an interest in internal communication, while white dots represent lack of such interest; squares emphasize an interest in corporate strategy and projects development, the circles highlight lack of such interest) 
According to the data in Figure 6, only three employees (U1, U30, U40) used the internal social network to share knowledge about insurance best practices and operational issues, while others were more involved in developing marketing strategies. One interesting aspect at this level was related with the relationship established between U30 and U22. As we can observe, the first one shared his/her knowledge about best practices and operational issues while the second acquired them without using them directly. He/she may adapt the knowledge that he/she received from U30 to the marketing strategies area, a subject in which he/she is interested in. He/she could acquire knowledge to use it latter. Last, but not least, we noticed that U11, U21, U42, and U50 acted as knowledge gatekeepers when it came to marketing strategies and policies.



Figure 6. Distribution of SPUK's employees based on their interest in best practices and marketing strategies

(black dots denote an interest in best practices and operational issues, while white dots represent lack of such interest; squares emphasize interest in marketing strategies and policies, while circles highlight lack of such interest)

If local issues and events were taken into account (Figure 7), employees' activity in the internal social network significantly reduced. U16 acted as a gatekeeper and controlled the knowledge flows about local issues between U22 and the group that he/she managed, constituted by U53, U54, U55, U56, and U57. According to the same framework, U27 acted as a knowledge broker and mediated the knowledge flows between U22 and U77. When it came to events, U22 was seen as an expert and he/she tended to share his/her knowledge with $\mathrm{U} 2$ and $\mathrm{U} 36$. 


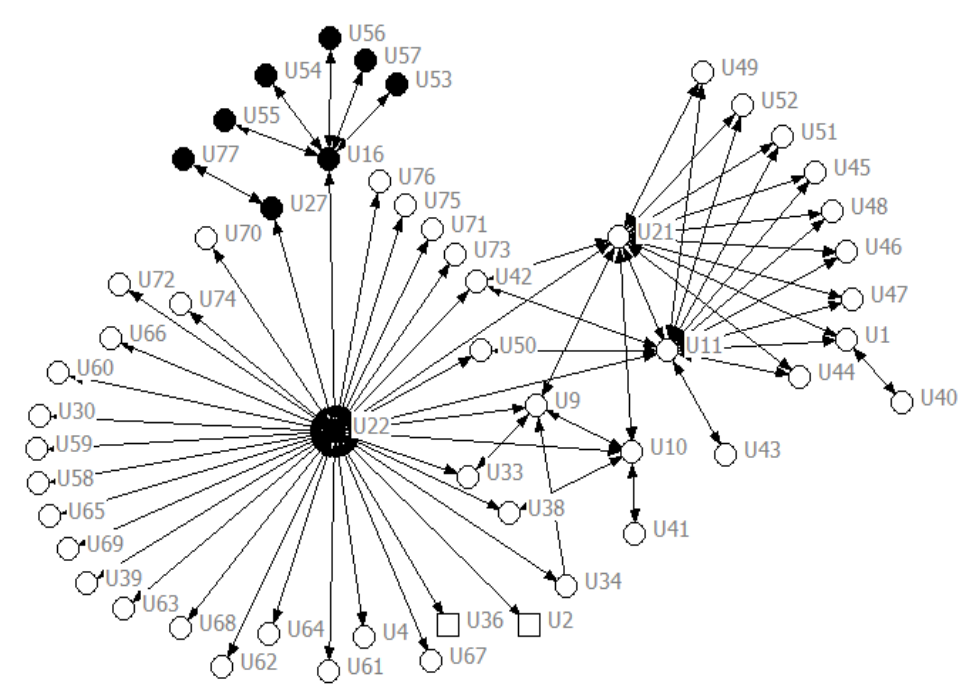

Figure 7. Distribution of SPUK's employees based on their interest in local issues and events

(black dots denotes an interest in local issues, while white ones represent lack of such interest; squares emphasize an interest in events, while circles highlight lack of such interest)

When focusing on the network's characteristics (Table 2), we noticed that 9,900 observations had been made, which ranged from 0 to 1 . Ties amounted to 143 , which meant that from February 17, 2014 to February 16, 2015, 143 knowledge flows crossed SPUK's internal social network. This could be an encouraging result if we take into account the cultural specificity and SPUK's field of activity; operating in the financial sector where rumors have a devastating effect, together with the influence of cultural particularities, may increase employees' orientation towards data confidentiality, and may make them skeptical to sharing their knowledge in an online environment. Therefore, the average value of ties was 0.014 , which emphasized that only $1.4 \%$ of the potential knowledge flows had actually been established. In other words, the network possessed a lot of potential that had not been yet exploited. Its potential was related with the topics that are usually approached in the internal social network, namely: (i) internal communication; (ii) corporate strategy and projects development; (iii) best practices and operational issues; (iv) marketing strategies and policies; (v) local issues; and (vi) events.

Table 2. Descriptive statistics of the internal network

\begin{tabular}{|l|l|r|}
\hline No. & \multicolumn{1}{|c|}{ Indicator } & \multicolumn{1}{c|}{ Value } \\
\hline 1. & Mean & 0.014 \\
\hline 2. & Std. Dev. & 0.119 \\
\hline 3. & Sum & 143.000 \\
\hline 4. & Variance & 0.014 \\
\hline 5. & SSQ & 143.000 \\
\hline 6. & MCSSQ & 140.934 \\
\hline 7. & Euc. Norm & 11.958 \\
\hline 8. & Minimum & 0.000 \\
\hline 9. & Maximum & 1.000 \\
\hline 10. & No. of obs. & 9900.000 \\
\hline 11. & No. missing & 0.000 \\
\hline
\end{tabular}

The Euclidean norm was also provided and measured the level of dissimilarity between network members. Since its value equaled 11.958 , we could argue that there were plenty of 
dissimilarities between members, and knowledge had to cross a long distance in order to pass from one employee to another.

Based on the data in Table 3, which includes the results for both the classical and bootstrap methods, network density was statistically significant. In the first case, the difference between the null and observed values (network density was 0.0144) was -0.9856 while sampling variability was estimated at 0.0012. Therefore, the test statistic $(0.9856 / 0.0012=821.33)$ was highly significant as a t-test with $N-1$ degrees of freedom. In the second case, when 5,000 networks were constructed by sampling random sub-sets of nodes, the sampling distribution mean equaled 0.0184 , while the standard deviation was 0.0081. Using the alternative standard error based on random draws from the observed sample, the test statistic was -122.1282 , which was also significant $(p=0.0002)$.

Table 3. The statistical significance of network density

\begin{tabular}{|l|l|r|}
\hline No. & \multicolumn{1}{|c|}{ Indicator } & \multicolumn{1}{c|}{ Value } \\
\hline 1. & Parameter value & 1.000 \\
\hline 2. & Network's density & 0.0144 \\
\hline 3. & Difference & -0.9856 \\
\hline 4. & Variance of ties & 0.0142 \\
\hline 5. & Classical estimate of SE & 0.0012 \\
\hline 6. & Number of bootstrap samples & 5000 \\
\hline 7. & Estimated standard error for density & 0.0081 \\
\hline 8. & Z-score & -122.1282 \\
\hline 9. & Average bootstrap density & 0.0184 \\
\hline 10. & p & 0.0002 \\
\hline
\end{tabular}

If the distinction between past and current knowledge flows is taken into account, past evolution reflects the monthly knowledge flows that crossed the internal social network from May to December 2014, while the current evolution emphasizes the results obtained in January 2015. If we take into account the monthly evolution of network density (Figure 8), then we find that it follows a sinusoidal pattern; the network did not reach a mature development stage and still had a lot to offer. Consequently, following the same line as Burt (2001), who demonstrated that high network density generated a high degree of redundancy in the knowledge sharing process, we found that the low density recorded by SPUK's internal social network had a positive influence on the knowledge sharing process.

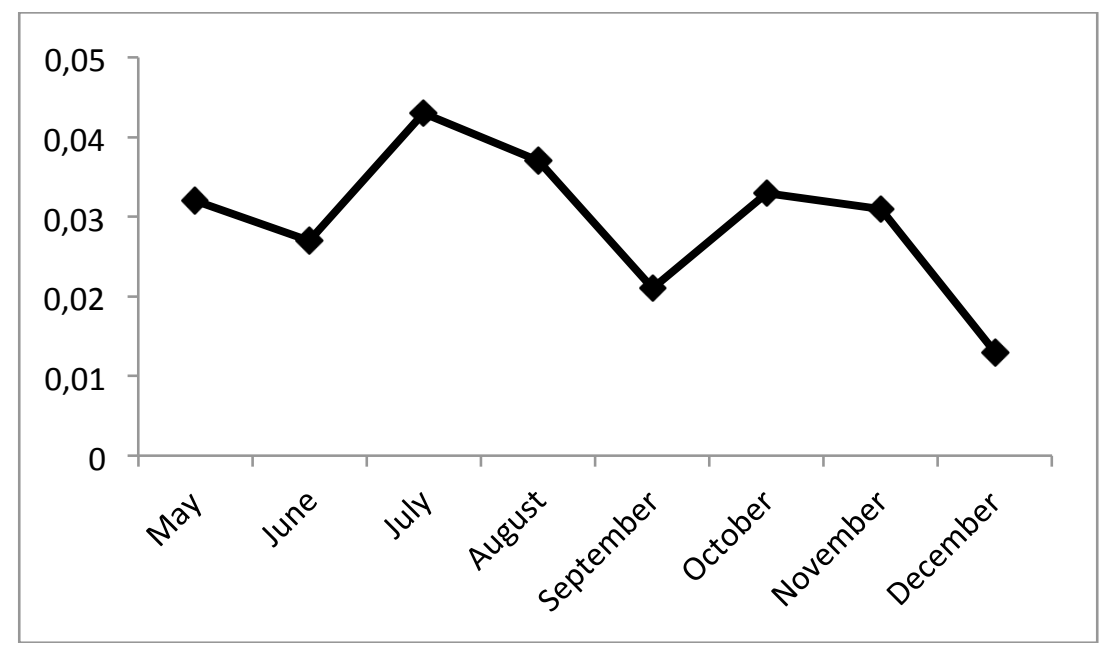

Figure 8. Monthly evolution of network's density 
Depending on the status of their account and on the number of logins, the members of the last category of employees can be described as "knowledge absorbers". If they are active and keep logging in, but do not interact with others, then they can use SPUK's internal social network to acquire necessary knowledge. In other words, they remain informed, but do not inform others; they acquire the knowledge posted by colleagues, but do not share what they know. Still, it is difficult to analyze the level or frequency of readership as it leaves no traceable data (Lakhani and von Hippel, 2003). However, some traceable evidence is identified in the behaviour adopted by active SPUK internal social network members. One such case is user U9, who receives knowledge from co-workers (the density of knowledge inflows is 0.051), but shares only a small part of what he/she knows (the density of knowledge outflows is 0.040 ). The strategy adopted by user U34 differs significantly: he/she concentrates on knowledge dissemination and not on knowledge absorption. Therefore, the density of the knowledge outflows is twice as high as that of knowledge inflows, which equals 0.010 .

In order to better understand the structure and characteristics of SPUK's internal social network, we need to take into account the degree, betweenness and closeness centrality of the 100 employees who represent the research sample. The employees who obtain the best results are presented in Table 4. They are the pillars of the internal social network, namely: U11, U21, and U22. Although their rank varies according to the reference framework, they are a critical resource for SPUK in terms of knowledge flows and knowledge sharing efficiency. Their expertise is recognized by others, they act as intermediates of the knowledge that flows from one employee to another, and from one group to another, and they are aware of who gatekeepers are and how they can be motivated to cooperate. Given these peculiarities, decision-makers should take them into account when devising organizational policies and practices because they can influence others, and can transmit information and knowledge to a large number of employees in a short time.

Table 4. Main indicators of the social network analysis

\begin{tabular}{|c|c|c|c|}
\hline Centrality & Rank & Employee & Description \\
\hline \multirow[t]{5}{*}{ Degree } & 1 & U22 & \multirow{5}{*}{$\begin{array}{l}\text { They are the leaders or experts of the network; } \\
\text { U22 is an expert in events, U16 is an expert in } \\
\text { local issues, U11 and U21 are leaders in the area } \\
\text { of marketing strategies and policies, while U9 is a } \\
\text { leader in the area of corporate strategy and } \\
\text { projects developments. } \\
\text { - They know what they know and are open to share } \\
\text { it. } \\
\text { - They know what they do not know and are open } \\
\text { to acquire it from others. }\end{array}$} \\
\hline & 2 & U11 & \\
\hline & 3 & U21 & \\
\hline & 4 & U16 & \\
\hline & 5 & U9 & \\
\hline \multirow[t]{5}{*}{ Betweenness } & 1 & U22 & \multirow{5}{*}{$\begin{array}{l}\text { - They facilitate knowledge sharing. } \\
\text { - They control the knowledge that goes in and out } \\
\text { of certain groups. }\end{array}$} \\
\hline & 2 & U11 & \\
\hline & 3 & U16 & \\
\hline & 4 & U21 & \\
\hline & 5 & U10 & \\
\hline \multirow[t]{5}{*}{ Closeness } & 1 & U22 & \multirow{5}{*}{$\begin{array}{l}\text { - They are capable of spreading their knowledge to } \\
\text { all other network members. } \\
\text { - They know who the gatekeepers of each group are } \\
\text { and know how to approach them. }\end{array}$} \\
\hline & 2 & U21 & \\
\hline & 3 & U11 & \\
\hline & 4 & U10 & \\
\hline & 5 & U9 & \\
\hline
\end{tabular}


In the analysis of the knowledge flows that these employees tend to send and receive (Table 5), we notice a balance between the knowledge that flows in and out for most of them. The only exception is employee U9, who receives more knowledge than he/she sends; the density of tie sending equals 0.040 , while that for tie receiving is 0.051 . By correlating these results with the fact that U9 has a high level of degree and closeness centrality, we state that he/she focuses more on acquiring knowledge than sharing knowledge. Given his/her position in the network, we argue that he/she concentrates mainly on the "know who" type of knowledge. Thanks to this, U9 manages to obtain a central position without having to increase the level of knowledge outflows. These results are in line with his/her job responsibilities; as a manager, he/she must know who he/she should contact in certain situations, who is responsible for specific issues, and to whom he/she should delegate responsibility.

Table 5. Descriptive statistics for the main actors of the internal network

\begin{tabular}{|l|c|c|c|c|c|c|c|c|c|c|c|c|}
\multicolumn{1}{c|}{} & \multicolumn{2}{c|}{ U9 } & \multicolumn{2}{c|}{ U10 } & \multicolumn{2}{c|}{ U11 } & \multicolumn{2}{c|}{ U16 } & \multicolumn{2}{c|}{ U21 } & \multicolumn{2}{c|}{ U22 } \\
\cline { 2 - 12 } \multicolumn{1}{c|}{} & Out & In & Out & In & Out & In & Out & In & Out & In & Out & In \\
\hline Mean & 0.040 & 0.051 & 0.051 & 0.051 & $\mathbf{0 . 1 4 1}$ & $\mathbf{0 . 1 4 1}$ & 0.061 & 0.061 & $\mathbf{0 . 1 4 1}$ & $\mathbf{0 . 1 4 1}$ & $\mathbf{0 . 3 5 4}$ & $\mathbf{0 . 3 5 4}$ \\
\hline Std.Dev & 0.197 & 0.219 & 0.219 & 0.219 & $\mathbf{0 . 3 4 8}$ & $\mathbf{0 . 3 4 8}$ & 0.239 & 0.239 & $\mathbf{0 . 3 4 8}$ & $\mathbf{0 . 3 4 8}$ & $\mathbf{0 . 4 7 8}$ & $\mathbf{0 . 4 7 8}$ \\
\hline Sum & 4.000 & 5.000 & 5.000 & 5.000 & $\mathbf{1 4 . 0 0 0}$ & $\mathbf{1 4 . 0 0 0}$ & 6.000 & 6.000 & $\mathbf{1 4 . 0 0 0}$ & $\mathbf{1 4 . 0 0 0}$ & $\mathbf{3 5 . 0 0 0}$ & $\mathbf{3 5 . 0 0 0}$ \\
\hline Variance & 0.039 & 0.048 & 0.048 & 0.048 & $\mathbf{0 . 1 2 1}$ & $\mathbf{0 . 1 2 1}$ & 0.057 & 0.057 & $\mathbf{0 . 1 2 1}$ & $\mathbf{0 . 1 2 1}$ & $\mathbf{0 . 2 2 9}$ & $\mathbf{0 . 2 2 9}$ \\
\hline SSQ & 4.000 & 5.000 & 5.000 & 5.000 & $\mathbf{1 4 . 0 0 0}$ & $\mathbf{1 4 . 0 0 0}$ & 6.000 & 6.000 & $\mathbf{1 4 . 0 0 0}$ & $\mathbf{1 4 . 0 0 0}$ & $\mathbf{3 5 . 0 0 0}$ & $\mathbf{3 5 . 0 0 0}$ \\
\hline MCSSQ & 3.838 & 4.747 & 4.747 & 4.747 & $\mathbf{1 2 . 0 2 0}$ & $\mathbf{1 2 . 0 2 0}$ & 5.636 & 5.636 & $\mathbf{1 2 . 0 2 0}$ & $\mathbf{1 2 . 0 2 0}$ & $\mathbf{2 2 . 6 2 6}$ & $\mathbf{2 2 . 6 2 6}$ \\
\hline Euc.Norm & 2.000 & 2.236 & 2.236 & 2.236 & $\mathbf{3 . 7 4 2}$ & $\mathbf{3 . 7 4 2}$ & 2.449 & 2.449 & $\mathbf{3 . 7 4 2}$ & $\mathbf{3 . 7 4 2}$ & $\mathbf{5 . 9 1 6}$ & $\mathbf{5 . 9 1 6}$ \\
\hline
\end{tabular}

\section{Phase 4. Future trends and strategic implications}

If we take a look at Figure 9, the situation of U9 becomes even more interesting; some users are no longer active in SPUK's internal social network, and U9 is one of them. Based on the status of their account on February 16, 2015, employees were split into two categories: those who were still active on the internal social network and those who had suspended or deleted their account. Therefore, in Figure 9, black dots represent users who were still active on the company's internal social network, while white dots denote users who had either deleted or suspended their account on the firm's communication platform. Their "disappearance" generated knowledge loss at the internal social network level. Most have a dependence relationship, and are connected with only one co-worker; however, not the same can be said of U9, U33, U38, U42, and U50, who connect with various co-workers. The first has a high degree and closeness centrality, while the other ones take an intermediate position (they mediate the relationships between two employees or more). Their disappearance had consequences on both the network content and network structure. 




Figure 9. Distribution of SPUK's employees based on the state of their account

First of all, their disappearance generated knowledge loss; the company and other employees lost their access to users' cognitive, emotional and spiritual knowledge and, therefore, could no longer obtain users' advice or perspectives on certain issues. Nevertheless, it is necessary to take into account that such knowledge loss is recorded only at the internal social network level, and not at the organizational level, as employees are still hired at SPUK. Although they have the possibility of sharing their knowledge within organizational boundaries, chances are that their knowledge flows to a few employees (most probably, to the members of the same team or department). On the one hand, this will increase redundant activities. For instance, when a similar problem like that solved by department X, appears in department $Y$, members of the latter will spend a similar or larger amount of resources to "reinvent the wheel", to become familiar with details and to find possible solutions (Huang, 2009). On the other hand, this may decrease the innovative potential of both the team and company as a whole. By sharing knowledge, employees avoid redundancy of knowledge production and are capable of innovating, regardless of where knowledge was initially sourced and stored (Huang, 2009). As they do not do this, employees concentrate on the specific knowledge they have and can obtain a limited perspective on the issue. This could be the case of SPUK as most teams are not interdisciplinary.

Secondly, the network starts to fragmentize. If the disappearance of U38, U42 and U50 did not affect the knowledge sharing process among U22 and U10, U11 and U21, this could not be stated for U9. Once U9 became inactive, knowledge was no longer shared between U21 and U34. According to the results generated by Holland and Leinhardt's P1 model, there are an $83 \%$ of chances for knowledge to flow between U34 and U9 (guaranteed by a residual value of 0.14 ) and only $15 \%$ of chances for a direct knowledge flow between U34 and U21 (residual value equal to -0.15 ). This may generate communication issues or could stimulate direct collaboration between the two of them.

On a global level, the P1 model results, presented in Table 5, emphasize that bidirectional knowledge flows are more likely to cross the internal social network than unidirectional ones; this assumption is supported by the global tendency in the whole network toward reciprocity (25.7451) being positive and significantly larger than the absolute overall density value (-15.4355). Besides, it should be noted that the model's coefficients are logarithmic probabilities, which means that a one unit increase would involve a 2.7 increase in probability.

Nevertheless, at the individual level, Holland and Leinhardt's P1 model can be used to determine which employees could have a future influence on knowledge sharing, by increasing future generated or received knowledge flows. Future generated knowledge flows 
are assumed to be related with employees' expansiveness, while future received knowledge flows depend on employees' popularity. In other words, the vast expansiveness of an employee will reflect his/her interest in disseminating his/her knowledge to others; he/she will seek to transmit messages and to influence others. The high popularity of an individual will reflect his/her willingness to receive knowledge from others; he/se will be more oriented to learning from others experiences than to sharing his/her values, emotions, beliefs, ideas, experiences and other knowledge types.

Given the results generated by applying the P1 model at SPUK's internal social network level, it can be assumed that U34's popularity will increase, while U10, U11, U16, U21, and U22 will maintain the same pattern, and their expansiveness will widen (Table 6). All six will seek to influence others, to facilitate knowledge sharing, and to control knowledge flows. The "attractiveness" of other network members will increase, and they will be influenced and act as a "knowledge repository". Among the storytellers who act as middle-managers, it is important to note that U10 and U21 will focus on sharing knowledge, while their co-worker U34 will concentrate on receiving knowledge. In other words, the first two will be better connected with the group, while the last one will be better informed as he/she will receive knowledge from various sources. Further analyses are needed to determine whether this behavior will appear due to either managers' leadership skills or their job experience. We can observe that non-managers will concentrate on increasing their popularity, and will try to acquire knowledge from various sources so they can acquire a more complete image upon reality.

Table 6. P1 analysis of the internal network

\begin{tabular}{|c|c|c|c|c|}
\hline \multirow{2}{*}{ No. } & \multirow{2}{*}{ User } & \multirow[t]{2}{*}{ General job title } & \multicolumn{2}{|c|}{ Coefficients } \\
\hline & & & Alpha & Beta \\
\hline 1. & U1 & Internal Advisor & 0.341 & 0.740 \\
\hline 2. & U10 & Storyteller & 1.090 & 1.042 \\
\hline 3. & U11 & Internal Communications Manager & 2.483 & 1.575 \\
\hline 4. & U16 & Project Consultant & 1.332 & 1.176 \\
\hline 5. & U21 & Storyteller & 2.429 & 1.629 \\
\hline 6. & U22 & Internal Communications Partner & 3.274 & 2.832 \\
\hline 7. & U27 & Facilitator & -0.158 & 0.475 \\
\hline 8. & U34 & Storyteller & 8.776 & -9.535 \\
\hline 9. & U44 & Personal Advisor & -0.050 & 0.364 \\
\hline 10. & $\mathrm{U} 45$ & Personal Advisor & -0.040 & 0.355 \\
\hline 11. & U46 & Trading Administrator & -0.031 & 0.345 \\
\hline 12. & U51 & Business Support & 0.015 & 0.299 \\
\hline 13. & U52 & Clerical Assistant & 0.024 & 0.290 \\
\hline 14. & G-Square & & & 260.78 \\
\hline 15. & DF & & & 3550 \\
\hline 16. & Theta & & & -15.4355 \\
\hline 17. & Rho & & & 25.7451 \\
\hline
\end{tabular}

According to the results generated by applying PLS-SEM, the probability of employees continuing to share their knowledge in the network is influenced by network heterogeneity and structure (Annex 1).

According to the data in Table 8, it can be assumed that network heterogeneity and structure strongly influence both employees' future knowledge sharing intention (acting as a knowledge diffuser) and their intention of remaining isolated (acting as a knowledge repository). However, the relationship between network heterogeneity and structure, and employees' future knowledge sharing intention $(\beta=0.673, p<0.05)$, is stronger than that 
established between network heterogeneity and structure, and employees' future intention of remaining isolated $(\beta=0.413, p<0.05)$. Nevertheless, the negative correlation found between employees' future intention of acting as a knowledge diffuser and their decision to act as a knowledge repository must be taken into consideration $(\beta=-0.956, p<0.05)$. These results are in line with the insights of the social value orientation theory; employees' future knowledge sharing intention is influenced not only by group characteristics, as various studies have claimed (Hu, 2013; Tasselli, 2015), but also by the perceived social outcomes that they may gain.

Table 8. Testing the relationships established between network heterogeneity and structure, and employees' future intention of knowledge sharing

\begin{tabular}{|c|r|r|r|r|}
\hline Hypothesis & Standard deviation & t & p & Status \\
\hline H1 & 0.220 & 3.065 & 0.002 & Supported \\
\hline H3 & 0.175 & 2.360 & 0.019 & Supported \\
\hline
\end{tabular}

As we can notice in Table 9, SPUK's situation will switch from a more decentralized to a more centralized knowledge sharing process. If groups are formed by 3-4 members, soon knowledge will be retained and disseminated by only $2-3$ employees. This proves that SPUK's policies are not as efficient as desired in terms of stimulating employees' interest in sharing their knowledge through internal social networks. They caught their attention at the beginning, but did not manage to maintain it. From this point of view, the future evolution of SPUK's internal social network seems to describe an involution process; it will go back to the first theories developed in the knowledge management field, according to which "knowledge is power" and whoever has it, it has an advantage.

Table 9. Past and future groups of influence on SPUK's internal social network

\begin{tabular}{|l|l|l|}
\hline No. & \multicolumn{1}{|c|}{ Past group of influence } & \multicolumn{1}{|c|}{ Future group of influence } \\
\hline 1 & $\mathrm{U} 9, \mathrm{U} 10, \mathrm{U} 21, \mathrm{U} 22$ & $\mathrm{U} 10, \mathrm{U} 21, \mathrm{U} 22$ \\
\hline 2 & $\mathrm{U} 9, \mathrm{U} 22, \mathrm{U} 33$ & - \\
\hline 3 & $\mathrm{U} 9, \mathrm{U} 22, \mathrm{U} 34$ & $\mathrm{U} 22, \mathrm{U} 34$ \\
\hline 4 & $\mathrm{U} 11, \mathrm{U} 21, \mathrm{U} 22, \mathrm{U} 42$ & $\mathrm{U} 11, \mathrm{U} 21, \mathrm{U} 22$ \\
\hline 5 & $\mathrm{U} 11, \mathrm{U} 22, \mathrm{U} 50$ & $\mathrm{U} 11, \mathrm{U} 22$ \\
\hline
\end{tabular}

Synthesizing, by applying SNA techniques to SPUK's internal social network, we managed to: identify knowledge flows; determine the actors who play a crucial role in the knowledge sharing process; identify the employees who may generate internal knowledge loss; predict future knowledge flows that may occur among SPUK's employees. In other words, we determined: (i) the employees who play an important role in the organizational processes, by possessing the necessary knowledge and being willing to share it; and (ii) who can interfere with, and who is going to influence organizational processes (who controls the knowledge flows within and between groups).

\section{Final discussions and implications}

Based on an interpretative approach, it has been proved that SNA can be a tool for analyzing and predicting the organizational knowledge flows of a private organizational social network as it is capable of identifying leaders and followers, and it determines the chances of certain employees interacting. Not only can the main actors of an organization's internal network be identified and emphasized, but also their connections and knowledge flows. Besides, the future knowledge flows that may occur and the changes that may occur in 
the groups of influence composition can be worked out and analyzed. These findings have both theoretical and practical implications.

\section{Theoretical implications}

The approach adopted herein is in line with previous studies which have shown that networks are a critical resource for firms as they provide an alternative tool for sharing scientific and technological knowledge (Salavisa et al., 2012), and also for knowledge management improvement (Singh et al., 2015).

Most previous studies (Hu, 2013; Tasselli, 2015) have addressed situations of conscious, controlled knowledge sharing and use of questionnaires for data collection. Therefore, two issues appear: (i) neglecting knowledge that is unconsciously shared, and (ii) subjective biases that interfere with data collection. Firstly, knowledge sharing involves more than just the intentional, mechanical and interpersonal movement of knowledge; it is mediated by trust, and also includes emotions, values, beliefs, ideas and experiences. As mentioned before, not everything boils down to "know how" and explicit knowledge; Huang (2009) has demonstrated that members need to understand who knows what, while $\mathrm{Hu}$ (2013) has claimed that people with a large number of social connections strongly impact the diffusion of innovations. This gap is bridged by using an internal social network that shows who knows what and who knows who. Secondly, when it comes to analyzing knowledge sharing and networks, most researchers are tempted to use questionnaire-based surveys; although they provide a large quantity of data in a short time, they are affected by several biases, like current moment bias, anchoring effect or heuristic effects. This problem is solved by resorting to an internal social network capable of providing real data on how knowledge is shared and by whom.

Besides, the current research goes even further by extending the reference framework in content and time horizon terms. The focus lies not only on explicit knowledge, but also on tacit knowledge. Through an internal social network, employees are able to interact and share their experiences, ideas, emotions, values and beliefs with one another. Thus, the presented methodology brings forward the knowledge flows that occur among employees and also emphasizes who knows who. Therefore, an important issue has been addressed but is neglected by organizational studies despite the fact that it has been proved that hyperlinked employees are similar to opinion leaders and become prominent sources in solving uncertainties, diminishing the risks, and diffusing innovations ( $\mathrm{Hu}, 2013)$. Nevertheless, it offers a potential solution as to how work-teams can be established, by complementing the elements highlighted by Walter and Zimmermann (2015).

On the other hand, the current literature is extended, as this paper proposes a methodology capable of predicting future knowledge flows from a private organizational social network. This issue has not yet been addressed by the knowledge management scholars. Based on the P1 model, employees may influence future knowledge flows can be identified. Moreover, their attractiveness and expansiveness are emphasized.

Nevertheless, the developed methodology is capable of identifying the network's sources of vulnerability: isolated members who may act as "knowledge absorbers", and those who represent gatekeepers, control the knowledge that goes in and out of certain groups. Last, but not least, it brings forward the internal knowledge loss issue. As a result of members disappearing from the network, the company and other employees will lose access to users' cognitive, emotional and spiritual knowledge; and they will no longer obtain users' advice or perspectives on certain issues. Although they may still have the chance to share their knowledge within organizational boundaries through emails and direct interactions, the chances are that their knowledge will flow to a few employees (it will most probably reach members of the same team or department). On the one hand, this will increase redundant activities since some employees will spend a similar or a larger amount of resources to 
become familiar with details and to find possible solutions (Huang, 2009). This may reduce the innovative potential of both the team and company as a whole. By sharing knowledge, employees will avoid redundant knowledge production and will be capable of innovating, regardless of where the knowledge was initially sourced and stored (Huang, 2009).

Finally, networks and knowledge sharing are presented as success factors in the organizational processes developed in knowledge-intensive sectors, especially in those related with technology and research (Hu, 2013; Salavisa et al., 2012; Singh et al., 2015). They overlook the fact that knowledge sharing occurs and is necessary in all fields. These issues are neglected by academics, who analyze the field of regular services like, wholesales, insurances, cleaning etc. The proposed methodology presented herein aims to bridge this gap by determining how knowledge sharing occurs in an insurance company, who gets involved in the process and who may influence future knowledge flows.

\section{Practical implications}

This research offers decision-makers a tool to identify who are the employees with many social links with others. By knowing this, they will be able to enhance knowledge sharing efficiency. The organizational processes will be undoubtedly fostered in the organization, as it will be possible to apply actions to mitigate knowledge loss and to increase the degree of connection of employees. By knowing who knows who and who knows what, managers will have a complete image as to how to organize teams in order to foster their innovation potential and the company's capacity to react and adapt to market demands; they will know who can act as a leader of opinion, who can stimulate creativity, and who can foster or inhibit employees' participation in organizational processes.

This methodology also offers a solution for decision-makers to improve cooperation and communication at the internal network level. Furthermore, it brings forward a sensible issue: knowledge loss. Although collaboration is a must and occurs on a formal or informal basis, decision-makers should take into account the consequences that could emerge if one of the members leaves the network. They will not only leave with the knowledge that they have acquired in the network but this situation will also hinder others' access to their knowledge, expertise and experiences. As a consequence, other employees may spend time and money on finding a solution that has already been used before. In other words, an internal social network can also serve as a repository for the good practices and lessons learned.

\section{Conclusions and further research directions}

Social Network Analysis is capable of synthesizing the relationships and resource flows developed in the network, and can offer a complete image as to both the network's structure and quality, and about actors' characteristics. Accordingly, decision-makers can determine the results and pitfalls of current organizational policies and procedures, and can identify the measures they need to take to improve them. They can determine employees' interests and potential areas of expertise, who has the necessary knowledge and is willing to share it; who controls the knowledge flows within and between groups; and also who will influence the future knowledge flows.

Starting from these, this paper has presented an SNA-based methodology that, was applied to a private organizational social network from an insurance firm, and was able to: (i) identify the potential knowledge loss that could occur once a member becomes inactive on organization's social network; (ii) determine what subgroups exist and interact in the internal social network; (iii) study who the leaders are who facilitate cooperation and communication between internal network members; (iv) analyze how centralized the knowledge flows in the internal social network are; (v) determine who will act as a knowledge diffuser, by sharing what they know with co-workers, and who will act as a knowledge repository, by focusing on 
acquiring increasingly more knowledge; (vi) identify the elements that influence employees' future knowledge sharing intention.

Despite these implications, the research is limited by the size of the research unit and the characteristics of the analysis unit. The results cannot be extended to other companies in the same field of activity because this research focuses only on a single case study. Moreover, the relationships established among SPUK's employees are highlighted according to the interactions they had on the company's internal social network. The results could have been different if the offline knowledge sharing processes had been analyzed. Last, but not least, the analysis focuses on the internal social network and neglects the relationships established with external stakeholders.

Therefore, the following further research directions were identified: (i) to determine how the knowledge acquired from the internal social network is used in practice; (ii) to identify the elements that may determine that employees stop using an internal social network; (iii) to study the network's evolution by issues, people and departments; (iv) to examine who the leaders are who facilitate cooperation and communication among the internal network members and those from the external network; and (v) to analyze how centralized the knowledge flows between the internal and external social networks are.

Acknowledgment: "The research reported in this paper is supported by the European Commission for the project "Engaging in Knowledge Networking via an interactive 3D social Supplier Network (KNOWNET)" (FP7-PEOPLE-2013-IAPP 324408)".

\section{References}

Ahmad A, Bosua R, Scheepers R. 2014. Protecting organizational competitive advantage: A knowledge leakage perspective. Computers \& Security, 42, 27-39.

Albert R, Jcong H, Barabasi AL. 2000. Error and Attack Tolerance of Complex Networks. Nature, 406, 378-382.

Al-Oufi S, Kim H-N, El Saddik A. 2012. A group trust metric for identifying people of trust in online social networks. Expert Systems with Applications, 39, 13173-13181.

Arend RJ, Patel PC, Park HD. 2014. Explaining post-IPO venture performance through a knowledge-based view typology. Strategic Management Journal, 35(3), 376-397.

Baer M., Evans K., Oldham GR, Boasso A. 2015. The social network side of individual innovation: A meta-analysis and path-analytic integration. Organizational Psychology Review, 5(3), 191-223.

Behrendt S, Richter A, Trier M. 2014. Mixed methods analysis of enterprise social networks. Computer Networks, 75, 560-577.

Bernard HR, Killworth PD, Sailer L. 1981. Summary of Research on Informant Accuracy in Network Data and the Reverse Small World Problem. Connections, 4(2), 11-25.

Bernasek A. 2010. The Economics of Integrity. HarperCollins Publishers: New York.

Bianchi M, Chiaroni D, Chiesa V, Frattini F. 2011. Organizing for external technology commercialization: evidence from a multiple case study in the pharmaceutical industry. R\&D Management, 41, 120-137.

Borgatti SP, Li X. 2009. On social network analysis in supply chain context. Journal of Supply Chain Management, 45, 5-22. 
Burt RS. 2001. Structural Holes versus Network Closure as Social Capital. In Social Capital: Theory and Research, Nan L, Cook KS, Burt RS (eds.). Aldine De Gruyter: New York; 31-56.

Centola D, Macy M. 2007. Complex Contagions and the Weakness of Long Ties. American Journal of Sociology, 113, 702-734.

Chang CC, Hung SW, Cheng MJ, Wu CY. 2015. Exploring the intention to continue using social networking sites: The case of Facebook. Technological Forecasting and Social Change, 95, 48-56.

Chau M, Xu J. 2007. Mining Communities and Their Relationships in Blogs: A Study of Online Hate Groups. International Journal of Human-Computer Studies, 65, 57-70.

Chui M, Manylka J, Bughin J, Dobbs R, Roxburgh C, Sarrazin H, Sands G, Westergren M. 2012. McKinsey Global Institute. The Social Economy: Unlocking Value and Productivity through Social Technologies. McKinsey Global Institute: Washington.

Cyr S, Choo CW. 2010. The individual and social dynamics of knowledge sharing: An exploratory study. Journal of Documentation, 66(6), 824-846.

Deng S, Huang L, Guandong X. 2014. Social network-based service recommendation with trust enhancement. Expert Systems with Applications, 41, 8075-8084.

DiMicco JM, Geyer W, Millen DR, Dugan C, Brownholtz B. 2009. People sensemaking and relationship building on an Enterprise social network site. Proceedings of Hawaii International Conference on System Sciences.

Eisenhardt KM, Martin JA. 2000. Dynamic capabilities: what are they? Strategic Management Journal, 10(11), 1105-1121.

Evans D. 2008. Social Media Marketing: an Hour a Day. Wiley Publishing: Indianapolis.

Fernandes S, Belo A, Castela G. 2016. Social network enterprise behaviors and patterns in SMEs: Lessons from a Portuguese local community centered around the tourism industry. Technology in Society, 44, 15-22.

Foster P, Borgatti S.P., Jones C. 2011. Gatekeeper search and selection strategies: Relational and network governance in a cultural market. Poetics, 39, 247-265.

Freeman LC. 2004. The development of social network analysis: A study in the sociology of science. Empirical Press: Vancouver.

Garud R. 1997. On the distinction between know-how, know-why, and know-what. Advances in Strategic Management, 14, 81-101.

Giuliani E, Pietrobelli C. 2011. Social Network Analysis Methodoogies for the Evaluation of Cluster Development Programs. Technical Notes No. IDB-TN-317. Inter-American Development Bank.

Grant RM. 1996. Toward a knowledge-based theory of the firm. Strategic Management Journal, 117(2), 109-122.

Hajli N, Shanmugam M, Powell P, Love PED. 2015. A study on the continuance participation in on-line communities with social commerce perspective. Technological Forecasting and Social Change, 96, 232-241.

Holland P, Leinhardt J. 1981. An Exponential Family of Probability Distributions for Directed Graphs. Journal of the American Statistical Association, 76, 33-36.

Howison J, Wiggins A, Crowston K. 2011. Validity issues in the use of social network analysis with digital trace data. Journal of the Association for Information Systems, 12, 767-797.

$\mathrm{Hu}$ Y. 2013. Hyperlinked actors in the global knowledge communities and diffusion of innovation tools in nascent industrial field. Technovation, 33, 38-49.

Huang CC. 2009. Knowledge sharing and group cohesiveness on performance: An empirical study of technology R\&D teams in Taiwan. Technovation, 29, 786-797. 
Huizingh E. 2011. Open innovation: state of the art and future perspectives. Technovation, 31, 2-9.

Kamoche K, Kannan S, Siebers LQ. 2014. Knowledge-Sharing, Control, Compliance and Symbolic Violence. Organization Science, 35, 989-1012.

Kane GC, Alavi M, Labianca G, Borgatti SP. 2014. What's different about social media networks?: A framework and research agenda. MIS Quarterly, 38, 275-304.

Kane GC, Borgatti SP. 2011. Centrality-IS proficiency alignment and workgroup performance. MIS Quarterly, 35, 1063-1078.

Kwahk KY, Park DH. 2016. The effects of network sharing on knowledge-sharing activities and job performance in enterprise social media environments. Computers in Human Behavior, 55, 826-839.

Lakhani K, von Hippel E. 2003. How open source software works: "free"” user-to-user assistance. Research Policy, 32, 923-943.

Leonardi PM, Huysman M, Steinfield C. 2013. Enterprise social media: definition, history, and prospects for the study of social technologies in organizations. Journal of Computer-Mediated Communication,19,1-19.

Leroy P, Defert C, Hocquet A, Goethals F, Maes J. 2013. Antecedents of willingness to share information on Enterprise Social Network. In Organizational Change and Information Systems: Working and Living Together in New Ways, Spagnoletti P. (ed.). Springer: Berlin; 109-118.

Lind MR, Sulek, J.M. 2000. A methodology for forecasting knowledge work projects. Computers \& Operations Research, 27, 1153-1169.

Love JH, Roper S, Beyson JR. 2011. Openness, knowledge, innovation and growth in the UK business services. Research Policy, 40, 1438-1452.

Lu Y, Luo X, Polgar M, Cao Y. 2010. Social network analysis of a criminal hacker community. The Journal of Computer Information Systems, 51, 31-41.

Marabelli M, Newell S. 2012. Knowledge risks in organizational networks: the practice perspective. Journal of Strategic Information Systems, 21, 18-30.

Marcoulides GA, Chin WW, Saunders C. (2009). A Critical Look at Partial Least Squares Modeling. MIS Quarterly, 33(1), 171-175.

Nicolini D. 2011. Practice as the site of knowing: insights from the field of telemedicine. Organization Science, 22, 602-620.

Nonaka I, Takeuchi H. 1995. The knowledge creating company. Oxford University Press: New York.

Nonaka I, von Krogh G. 2009. Tacit knowledge and knowledge conversion: Controversy and advancement in organizational knowledge creation theory. Organization Science, 20, 635-652.

Pei M, Ramayah T, Suki N. 2011. Factors enhancing employed job seekers intentions to use social networking sites as a job search tool. International Journal of Technology and Human Interaction, 7, 38-54.

Premkumar G, Ramamurthy K, Liu HN. 2008. Internet messaging: an examination of the impact of attitudinal, normative, and control belief systems. Information \& Management, 45, 451-457.

Qualman E. 2009. Socialnomics: How Social Media Transforms the Way We Live and Do Business. John Wiley \& Sons: New Jersey.

Reagans RE, Zuckerman EW. 2008. Why Knowledge Does Not Equal Power: The Network Redundancy Trade-Off. Industrial and Corporate Change, 17, 903-944.

Ritala P, Olander H, Michailova S, Husted K. 2015. Knowledge sharing, knowledge leaking and relative innovation performance: An empirical study. Technovation, 35, 22-31. 
Robison L, Ritchie B. 2010. Relationship Economics: the Social Capital Paradigm and its Application to Business, Politics and Other Transactions. Gower Publishing: Surrey.

Rodriguez-Rodriguez R, Leon RD, Gómez-Gasquet P, Mula-Bru J. 2015. Measuring and linking social network knowledge exchange and organisational performance. International Conference on Sustainable Design and Manufacturing, 12-14 April, Seville, Spain.

Rohrbeck R, Thom N, Arnold H. 2015. IT tools for foresight: The integrated insight and response system of Deutsche Telekom Innovation Laboratories. Technological Forecasting and Social Change, 97, 115-126.

Sakalaki M, Sotiriou P. 2012. Pro-self orientation and preference for deceitful strategies: social value orientation, dispositional and behavioral correlates of economic opportunism. Studia Psychologica, 54(2), 157-165.

Salavisa I, Sousa C, Fontes M. 2012. Topologies of innovation networks in knowledgeintensive sectors: Sectoral differences in the access to knowledge and complementary assets through formal and informal ties. Technovation, 32, 380-399.

Sarker S, Ajuja M, Sarker S, Kirkeby S. 2011. The role of communication and trust in global virtual teams: a social network perspective, Journal of Management Information Systems, 28, 273-309.

Schonfeld E. 2008. Yammer Lauches at TC50: Twitter for Companies. TechCrunch: Palo Alto.

Scott KS, Sorokti KH, Merrell JD. 2016. Learning "beyond the classroom" within an enterprise social network system. Internet and Higher Education, 29, 75-90.

Shirky C. 2008. Here Comes Everybody: the Power of Organizing without Organizations. The penguin press: New York.

Singh H, Kryscynski D, Li X, Gopal R. 2015. Pipes, pools, and filters: How collaboration networks affect innovative performance. Strategic Management Journal. DOI: $10.1002 / \mathrm{smj}$.

Smith EP, Wise E, Rosen H, Rosen A, Childs S, McManus M. 2014. Top-Down, Bottom-Up, and Around the Jungle Gym: A Social Exchange and Networks Approach to Engaging Afterschool Programs in Implementing Evidence-Based Practices. American Journal of Community Psychology, 53(3-4), 491-502.

Soroka S.N. 2012. The gatekeeping function: Distributions of information in media and the real world. The Journal of Politics, 74(2), 514-528.

Steenkamp JBEM, Baumgartner H. 2000. On the use of structural equation models for marketing modeling. Journal of Research in Marketing, 17(2), 195-202.

Tasselli S. 2015. Social Networks and Inter-professional Knowledge Transfer: The Case of Healthcare Professionals. Organization Science, 36, 841-872.

Teece DJ, Pisano G, Shuen A. 1997. Dynamic capabilities and strategic management. Strategic Management Journal, 18(7), 509-533.

Trusov M, Bodapati AV, Bucklin RE. 2010. Determining influential users in Internet social networks. Journal of Marketing Research, 47(4), 643-658.

Tsai MT, Chang HC, Cheng NC, Lien CC. 2013. Understanding IT professionals' knowledge sharing intention through KMS: a social exchange perspective. Quality and Quantity, 47(5), 2739-2753.

Venkatesh V, Brown SA, Bala H. 2013. Bridging the qualitative-quantitative divide: guidelines for conducting mixed methods research in information systems. MIS Quarterly, 37, 21-54.

Walter M, Zimmermann J. 2015. Minimizing average project team size given multi-skilled workers with heterogeneous skill levels. Computers \& Operation Research http://dx.doi.org/10.1016/j.cor.2015.11.011. 
Wasserman S, Faust K. 1994. Social Network Analysis: methods and applications. Cambridge University Press: Cambridge.

West J, Bogers M. 2014. Leveraging external sources of innovation: a review of research on open innovation. Journal of Production Innovation Management, 31, 814-831.

Wu J, Goh KY, Tang Q. 2007. Investigating Success of Open Source Software Projects: A Social Network Perspective. ICIS 2007. Proceedings of International Conference on Information Systems 2007.

Wu L. 2013. Social network effects on productivity and job security: evidence from the adoption of a social networking tool. Information Systems Research, 24, 30-51.

Wuchty S, Uzzi B. 2011. Human Communication Dynamics in Digital Footsteps: A Study of the Agreement between Self-Reported Ties and Email Networks. PLoS ONE, 6(11), e26972.

Wyld DC. 2008. Management 2.0: a primer on blogging for executives. Management Research News, 31, 448-483.

Ye C, Ling H, Zou F, Lu Z. 2013. A new fingerprinting scheme using social network analysis for majority attack. Telecommunication Systems, 54, 315-331.

Yin FS, Liu ML, Lin CP. 2015. Forecasting the continuance intention of social networking sites: Assessing privacy risk and usefulness of technology. Technological Forecasting and Social Change, 99, 267-272.

Yoo D, No S. 2014. Ontology-based economics knowledge sharing system. Expert Systems with Applications, 41, 1331-1341.

Zhang X, Venkatesh V. 2013. Explaining employee job performance: the role of online and offline workplace communication networks. MIS Quarterly, 37, 695-722.

Zhou L, Wu W, Luo X. 2007. Internationalization and the performance of bornglobal SMEs: the mediating role of social networks. Journal of International Business Studies, 38, 673-690.

Zhu B, Watts S, Chen H. 2010. Visualizing social network concepts. Decision Support Systems, 49, 151-161. 
Annex 1. PLS-SEM model

. Model's validity and reliability

\begin{tabular}{|l|r|r|r|}
\hline \multicolumn{1}{|c|}{ Variable } & $\begin{array}{c}\text { Cronbach } \\
\text { Alpha }\end{array}$ & $\begin{array}{c}\text { Composite } \\
\text { Reliability }\end{array}$ & $\begin{array}{c}\text { Average Variance } \\
\text { Extracted }\end{array}$ \\
\hline Network heterogeneity \& structure & 0.719 & 0.742 & 0.584 \\
\hline Knowledge diffuser & 1.000 & 1.000 & 1.000 \\
\hline Knowledge repository & 1.000 & 1.000 & 1.000 \\
\hline
\end{tabular}

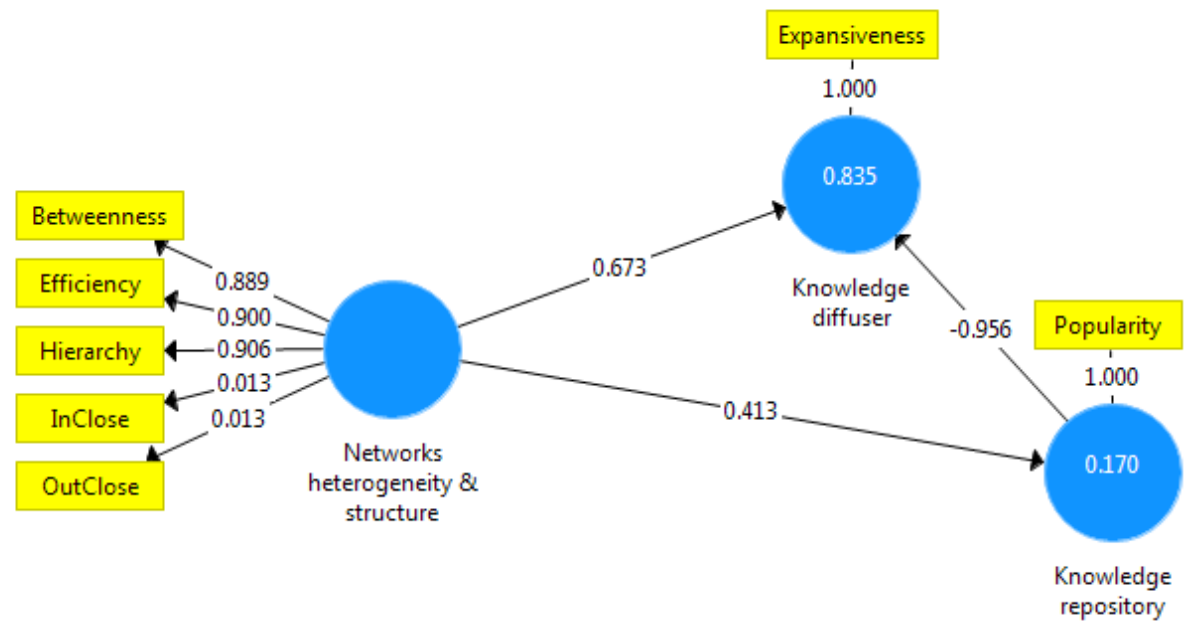

. Structural model 